\title{
New Invasive and Non-Invasive Ventilation Strategies for RDS Treatment of Preterm Babies
}

Citation for published version (APA):

Salvo, V. (2018). New Invasive and Non-Invasive Ventilation Strategies for RDS Treatment of Preterm Babies. [Doctoral Thesis, Maastricht University]. Datawyse / Universitaire Pers Maastricht. https://doi.org/10.26481/dis.20180912vs

Document status and date:

Published: 01/01/2018

DOI:

10.26481/dis.20180912vs

Document Version:

Publisher's PDF, also known as Version of record

\section{Please check the document version of this publication:}

- A submitted manuscript is the version of the article upon submission and before peer-review. There can be important differences between the submitted version and the official published version of record.

People interested in the research are advised to contact the author for the final version of the publication, or visit the DOI to the publisher's website.

- The final author version and the galley proof are versions of the publication after peer review.

- The final published version features the final layout of the paper including the volume, issue and page numbers.

Link to publication

\footnotetext{
General rights rights.

- You may freely distribute the URL identifying the publication in the public portal. please follow below link for the End User Agreement:

www.umlib.nl/taverne-license

Take down policy

If you believe that this document breaches copyright please contact us at:

repository@maastrichtuniversity.nl

providing details and we will investigate your claim.
}

Copyright and moral rights for the publications made accessible in the public portal are retained by the authors and/or other copyright owners and it is a condition of accessing publications that users recognise and abide by the legal requirements associated with these

- Users may download and print one copy of any publication from the public portal for the purpose of private study or research.

- You may not further distribute the material or use it for any profit-making activity or commercial gain

If the publication is distributed under the terms of Article $25 \mathrm{fa}$ of the Dutch Copyright Act, indicated by the "Taverne" license above, 


\section{SUMMARY AND DISCUSSION}

Despite important progress in perinatal medicine, respiratory distress syndrome (RDS) remains one of the most important causes of mortality and morbidity, especially in premature infants. The classic entity of neonatal respiratory distress syndrome, as a lung disease expressing predominant surfactant deficiency, is currently changing to a more complex disease of the extremely immature and the developing lung [1].

Although mortality and morbidity rates have decreased in term and preterm infants over the past three decades with the advent of antenatal steroids, the introduction of surfactant replacement therapy, and some advances in mechanical ventilation, long-term morbidity and the new BPD have not [1-3]. Despite using sophisticated ventilators and ventilation modes and advances in understanding mechanical ventilation, it is becoming evident that improvement in outcomes cannot be fully achieved by restoring normal lung physiology $[4,5]$. In this regard, a more specific, physiological, gentle and tailored ventilation strategy should be based on: i) careful data recording of perinatal history and treatments (i.e. steroids prophylaxis), ii) optimization of the delivery room and transitional phase management allowing to recruit and keep the lung open (i.e. SLI), iii) maintenance of FRC, supporting the spontaneous respiratory drive thus reducing apnea episodes and improving gas exchange, iv) decreasing the work of breathing, and v) limiting the VILI [69]. Altogether, it is essential to strike a balance between oxygenation, CO2 removal and the implications of higher than normal airway pressures, since optimizing one might come at the expense of the other. In addition to the ventilation strategies, the general treatment goals are: a) to protect the central nervous system; b) to guarantee haemodynamic equilibrium and appropriate PDA management; c) to give adequate nutritional intake and improve feed tolerance; d) to avoid infection.

VILI remains a major issue in neonatal intensive care. In this perspective, in the last few decades there has been widespread diffusion of N-CPAP, as a non-invasive respiratory support and as a primary approach in the management of RDS in preterm infants, due to its capacity to reduce the occurrence of BPD; however, N-CPAP failure rates still remain high (30-50\%) in preterm infants [10-13].

For these reasons, in recent years, the efforts of scientific and technological research have focused on trying to identify which NIV strategy was the most effective to avoid the use of MV or, whenever this was inevitable, what the best invasive or non-invasive ventilation technique could be to limit the time of $\mathrm{MV}$ and/or endotracheal intubation, in order to avoid VILI and BPD [14-15].

New ventilation techniques have been developed since 1980, such as HFOV, using tidal volumes smaller than anatomical dead space delivered at a very high rate of 600 to $900 \mathrm{bpm}$. The aim was to avoid the large volume swings seen with CMV thereby offering the potential for lung protective ventilation. Since volutrauma, atelectotrauma and to a lesser extent barotrauma are seen as main determinants in the development of VILI, HFOV could be considered as a lung protective mode of ventilation [16-18]. 
Moreover, since 1990 there has been considerable progress in the development of new devices and interfaces for NIV in preterm babies, that have made different techniques of NIV available and that could be more effective than N-CPAP, thus avoiding MV [19-20]. Indeed, the introduction of newer NIV methods has allowed to reduce the times of $\mathrm{MV}$ but it is still unclear whether they are really effective in reducing the BPD, also because these NIV techniques are quite heterogeneous and further large RCT are needed [21-23].

In this regard, the aims of this thesis were to compare the effectiveness of various techniques of ventilation respiratory support, both invasive and non-invasive, in order to reduce the need of CMV.

In Chapter 2, we investigated the effectiveness of two invasive respiratory strategies as first intention treatment, HFOV and CMV, in a randomized cohort of PN in whom antenatal steroids prophylaxis was not performed. We enrolled 88 VLBW infants, $<30$ wGA, who needed ventilation support (HFOV: $n=44 ; C M V: n=44$ ) within 2-h from birth, in three NICUs in which HFOV was usually used and with neonatologists staff who are highly experienced with both ventilation methods. We showed that HFOV, in a selected population of high risk newborns in which glucocorticoid prophylaxis was not performed, was more effective than CMV in terms of: shorter duration of ventilation, successful extubation, shorter duration of N-CPAP support after MV, and of hospitalization. Mortality, BPD and other secondary outcomes rates (PNX, NEC, ROP, IVH, etc.) did not differ between the two groups.

These promising results could be due to an early application of HFOV, as first intention ventilation treatment for RDS, associated with an open lung strategy [18,24-25]. This allowed recruiting the collapsed alveoli to achieve an adequate FRC and to stabilize the lung $[18,26]$. Furthermore, the maintenance of the newborn's spontaneous respiratory drive, with inspiration and expiration during the oscillation on a constant level of pressure (continuous distending pressure), could favor the weaning from invasive ventilation to $\mathrm{N}$ CPAP [16]. Despite the limitation due to the small sample size, the population of the study was homogeneous and bias was avoided by an early randomization (within 2-h from birth) and by excluding crossover between the two groups. Taking into account the high risk for RDS in the absence of GC-treatment, the potential bias of surfactant administration was avoided by administrating prophylactic surfactant to all infants admitted into the study.

All these aspects and more (e.g. delivery room management, SLI, early N-CPAP, surfactant, PDA management, etc.) could play an important role in the effectiveness of the ventilation strategy with a possible benefit on the reduction of VILI and BPD; however, well-designed and large trials are needed to define this [9].

Several trials to compare HFOV and CMV have been conducted in the last few years. The recent Cochrane meta-analysis of Cools et al. concluded that the use of elective HFOV compared with CMV results in a small reduction in the risk of BPD. However, the evidence 
is weakened by the inconsistency of this effect across trials, even after the meta-analysis was restricted to studies that applied a high lung volume strategy with HFOV [24]. Probably many factors, related both to the intervention itself as well as to the individual patient, interact in complex ways. In particular, clinical trials in which HFOV was compared to CMV are extremely heterogeneous in terms of: strategy of ventilation (HFOV first intention or rescue), open lung strategy performed or not, guaranteed volume applied in $\mathrm{CMV}$, setting parameters, surfactant treatment, time of randomization, cross-over between the two groups, $\mathrm{FiO} 2$ and $\mathrm{PaCO} 2$ tolerated, gestational age and birth-weight of the newborn $[16,24]$. In addition, the benefits could be counteracted by an increased risk of acute air leak.

A limitation of the present study was that, in the CMV group we did not perform an open lung strategy and/or a more protective ventilation method with volume guaranteed. The explanation resides in the fact that open lung strategy in the CMV group was not considered standard of care at that time.

Finally, the present observation offered further support to the debated issue on the best first intention invasive ventilation strategy for RDS treatment. Further multicenter RCTs in a larger population are therefore needed also to investigate HFOV effects on longterm outcomes.

Although invasive ventilation remains the only viable alternative and life-saving treatment for critically ill babies, neonatologists focus on what could be the best NIV strategy for RDS treatment. To date, N-CPAP is the most widely used method although not always effective $[6,10,14]$. Therefore, the aim of the research was to find alternative NIV techniques to enhance success and to decrease CMV rates $[23,27,28]$. Recently, two different methods of nasal ventilation support have been proposed: i) N-SIPPV, which is a modality of conventional ventilation, with intermittent peak inspiratory pressure delivered by a conventional ventilator, equipped with a nasal flow sensor to allow synchronization, and ii) BiPAP a non-synchronized modality, that provides two different levels of N-CPAP (lower and higher (PAP), whereby the infant can breathe spontaneously, delivered by a flow driver device associated with a nasal CPAP generator (CPAP variable flow, Coanda's effect) $[28,31]$.

Therefore, in Chapters 3 and 4 we evaluated the efficacy of these two NIV strategies (NSIPPV and BiPAP) for RDS treatment in VLBW infants. First, we conducted a retrospective study in 78 preterm newborns (N-SIPPV: $n=33$; BiPAP: $n=45$ ), and secondly a RCT bi-center trial enrolling 124 VLBW infants (N-SIPPV: $n=62$; BiPAP: $n=62$ ). Primary outcomes were the duration of ventilator support and NIV failure. In the RCT, the infants who had signs of respiratory failure at birth were treated with SLI and N-CPAP in addition to the American Academy of Pediatrics (AAP) recommendations [32]. The newborns included in the studies were not intubated and started on NIV support within 2-h from birth. Both studies showed similar results: the number of failures and duration of NIV support did not differ 
between the two strategies and were not GA-dependent. Moreover, no differences between groups were found regarding secondary outcomes (PNX, NEC, IVH, BPD, etc.). Of note, a high rate of EOS as a cause of failure in both groups was observed.

In our RCT, we found a low failure rate (18 out of 124 newborns, 15\%) and a short median duration of respiratory support (N-SIPPV: 89-h; BiPAP: 87-h). These data could be explained as the results of a more comprehensive strategy of RDS treatment starting with prenatal glucocorticoid prophylaxis (85-90\% for our population), delivery room management (SLI, early N-CPAP and early surfactant replacement by INSURE), first intention NIV support, physician's experience with NIV techniques and last but not least the nursing care $[9,20,32-34]$.

These are the first studies that compare two different NIV techniques with similar results and theoretical benefits. The theoretical advantages are: i) N-SIPPV through intermittent increase in pressure enhances tidal volume $(\mathrm{Vt})$, minute ventilation $(\mathrm{Vm})$, and $M A P$, resulting in better alveolar recruitment and gas exchange and decreasing the work of breathing (WOB) $[29,35]$, ii) BiPAP, using a much longer time of CPAPhigh $(0.8-1.5 \mathrm{sec})$ permits a complete respiratory cycle (inspiration and expiration) on the higher CPAP level (expiration way is always open), creating two different FRCs. BiPAP increases MAP, and FRC switching generates a Vt with a better gas exchange and reduces WOB $[14,19,36]$. Additional common NIV advantages, due to pressure changes, consist in the stimulation of spontaneous breathing that reduces failure risk due to apneas [37].

The present studies have some limitations such as the small sample size, which does not allow to show whether one technique was better than the other for BPD and mortality. Millar et al. compared two different NIV strategies (N-IPPV with conventional ventilator vs BiLevel-NIPPV with a flow driver, in which the peak pressure was much lower than the first group) by RCT, and did not observe any difference in the composite outcome of death or BPD [31]. Indeed, Millar and Kirpalani highlighted the uncertainty regarding the effects of N-IPPV devices: these may reflect the type of device and settings used, differences in the population and other inter-unit differences that are difficult to pinpoint [31].

Unfortunately, the abovementioned study does not clarify doubts about the superiority of the theoretical advantages of synchronized methods (N-SIPPV) as against the notsynchronized (BiPAP). Despite the known benefits of invasive triggered ventilation, one of the most important open questions is the efficacy of synchronization systems for nasal ventilation in preterm newborns. This holds for babies' characteristics and in part the technical limitations of the common trigger systems used for NIV (i.e. Graseby's capsule or flow sensor). In neonates, especially immature infants, it is very difficult to detect the inspiration phase as their spontaneous breathing is shallow and variable, thus breathing signals are weak or are superimposed upon a leakage flow. In our studies, for the N-SIPPV we used a device equipped with a specific nasal flow sensor (Giulia by Ginevri), that showed better tidal volume and minute volume compared with N-CPAP, in other studies, 
and, after INSURE technique, reduction of the need of MV; however, we found no difference in effectiveness between nasal-flow synchronized-IPPV and non-synchronized (BiPAP) strategies.

We concluded that both N-SIPPV and BiPAP strategies are equally effective in the early treatment of RDS in VLBW infants and suggested the need of further RCTs on larger populations to evaluate the effects of different NIV techniques on long-term outcomes.

Although these observations showed that N-SIPPV and BiPAP were equally effective, no answer was provided to the question of whether they were better than N-CPAP as primary treatment of RDS. Several authors in smaller study populations (N-IPPV or BiPAP versus $\mathrm{N}$-CPAP as control) and a meta-analysis reported: a) less need of $\mathrm{MV}, \mathrm{b}$ ) less risk of intubation in the first 72-h from birth, c) reduction of hospitalization duration and $\mathrm{O} 2$ dependency, and d) a promising decrease in BPD [15,21,22]. Conversely, Kirpalani et al., in a RCT, showed no difference for BPD and death at 28 days between N-CPAP and NIV strategies. Discrepancies may be explained by the inclusion in the N-IPPV group of different devices (ventilator driven or flow driver devices, synchronized or not synchronized, and BiLevel-CPAP) with different setting parameters [23].

In conclusion, at this stage, there are no studies comparing the aforementioned NIV techniques with the most widely used N-CPAP $[27,28]$. Therefore, in Chapter 5 , we conducted a multicenter retrospective study in order to investigate the effectiveness of the three different NIV methods as first intention treatment for RDS. We recruited 191 VLBW infants (N-CPAP: $n=66$; N-SIPPV: $n=62$, BiPAP: $n=63$ ). For N-CPAP, we used a variable flow system and for the other techniques the same equipment as in the previous studies. Newborns were supported in the DR and were admitted to the NICU on N-CPAP support and started on NIV support within 6-h from birth. The primary outcome was the failure rate within the first 5 days of life.

We showed that N-SIPPV/BiPAP, as first intention augmented the beneficial effects of $\mathrm{N}$-CPAP contributing to a significant reduced risk of failure in VLBW infants (N-CPAP: 22/66; N-SIPPV; 11/62; BiPAP 11/63). Moreover, no differences were found between the three groups regarding the secondary outcomes (PNX, NEC, IVH, BPD, etc.).

Of note, when we corrected the NIV failure rate for GA we found a significantly higher rate in the N-CPAP group, at 26-29 wGA, whilst no differences were observed in infants delivered at $<26$ wGA or $>29$ wGA. The absence of any differences in failure rate among the three NIV supports at $<26$ WGA may be due to: a) the severe lung immaturity and RDS itself, and $b$ ) to the reduced respiratory drive with very poor energy reserves to cope the high WOB to maintain FRC and adequate gas exchanges. Conversely, at 26-29 wGA, at a stage of increased lung maturity, N-SIPPV/BiPAP, with a different strategy, amplify the respiratory drive of the newborn and the effect of N-CPAP, thus obtaining: a) better lung recruitment with an adequate $\mathrm{FRC}$, thanks to the higher MAP, b) better gas exchanges due to an increase of $V t$ and $V m, c)$ a reduction of WOB, and d) decreased risk of apneas. 
Data on failure rate at $>29$ wGA can reasonably be due to non-respiratory causes such as EOS, PDA, PPHN, etc.

Finally, the absence of any difference between N-SIPPV (synchronized) and BiPAP (not synchronized) confirms previous observations and offers additional matter of debate about the real benefits and effectiveness of synchronized nasal ventilation $[14,28,31,38]$.

Our observation has several limitations. The main reside in: a) the study design since we conducted a retrospective not randomized investigation, although protocols were similar and standardized in all NICUs; b) the small sample size, and c) the choice made by the treating physician to use one or another NIV support due to device availability in NICU. Thus, we cannot exclude different attitudes of the neonatologists to use a specific NIV modality instead of the other.

However, our data show that N-SIPPV/BiPAP augment the beneficial effects of N-CPAP and contribute to a reduced risk of failure in VLBW infants complicated by RDS [21,22]. The use of N-SIPPV/BiPAP as first intention in ELBW/VLBW infants complicated by RDS is therefore suggested or when N-CPAP fails. Further multicenter RCTs in a larger population will be focused to address the following items: a) the most efficient method of NIV; b) the possible advantages of association with a lung recruitment strategy in DR (SLI); c) the real benefits of the less invasive method or of the strategy for surfactant administration; d) what would the real advantages of synchronization during NIV be, and e) what would the effect of NIV be on the reduction of VILI and/or BPD [15,39-43]. 